\title{
The Study on Small Generator using a Hydraulic for Sensor Nodes
}

\author{
Yeongseok Lee, Hong-geun Kim, Olly Roy Chowdhury, Changsun Shin, \\ Yongyun Cho and Jangwoo Park ${ }^{*}$ \\ Dept. Information and Communication Engineering, Sunchon National University, \\ 255 Jungangno, Suncheon, Jeonnam 540-950, Republic of Korea \\ \{kcl00kr,khg_david, ollyroy, csshin,yycho, jwpark\}@sunchon.ac.kr
}

\begin{abstract}
This paper is to realize an electric power generator utilizing wave force through hydraulic mechanism. The wave power generator using hydraulic mechanism is very useful since it produces energy in the ocean. This experiment used a check valve, oil pressure tube, and generator to embody the wave power generator through hydraulic mechanism. Check valve was used to make the fluid flow in one direction, and oil pressure tube for the movement of the fluid. The volume and pressure of the fluid in the structure were calculated. The factors which affected the volume and pressure of the fluid in the structure were analyzed. And the results from this study shall be applied to the actual marine construction, and utilized in the research for the reinforcement of the structure.
\end{abstract}

Keywords: hydraulic, hydraulic mechanism, New Renewable Energy, wave force, ocean wave energy, fish farm

\section{Introduction}

Recently the limitations of the fossil fuel such as petroleum, coal, and natural gas, the high price of gasoline, the riskiness of the atomic energy, and the environmental pollution make the demand for the New Renewable Energy steadily increase, and the relevant researches on it are progressively activated [1]. The authorities concerned in the Korean government now promote diverse enterprises. The Korean government currently drives the '20/25 plan' in Chile that shall appropriate the generation of the New Renewable Energy for the $20 \%$ of the total electrical power generation up to the year 2025 [2].

Ocean wave energy among the diverse New Renewable Energy possesses the merit that it has an ample source of available energy based on the wide distribution. Wave power generation means the power generation in the driving power of the motor converted from the potential energy of ocean wave energy [3]. Wave power generation has diverse practical application, for example, the generator itself can be used as a bulwark, and it can be installed anywhere at a buoy or lighthouse that is under the direct influence of wave force. Wave power generation industry allows an easy access because there is no open market formed yet, and Yongsu Trial Wave Power Generation Institution is domestically under construction. Hereafter in order for any prior occupation in the market, technical development to heighten the generation efficiency and to lessen the installation cost is essential [4].

Here this study introduces a miniaturized generator structure using hydraulic mechanism generating power only with the pressure of the wave power among the general wave power

${ }^{*}$ Corresponding Author 
generators that produce electricity by converting the potential and kinetic energy of ocean wave into mechanical movement.

In Chapter 2 this study explains the structure and movement of hydraulic mechanism, and in Chapter 3 shows the structure and design of the miniaturized generator using hydraulic mechanism. And in Chapter 4 will show the possibility of applications of the experiment processes and results, and in Chapter 5 will explain the improvement plan for the miniaturized generator structure with hydraulic mechanism.

\section{Hydraulic Mechanism}

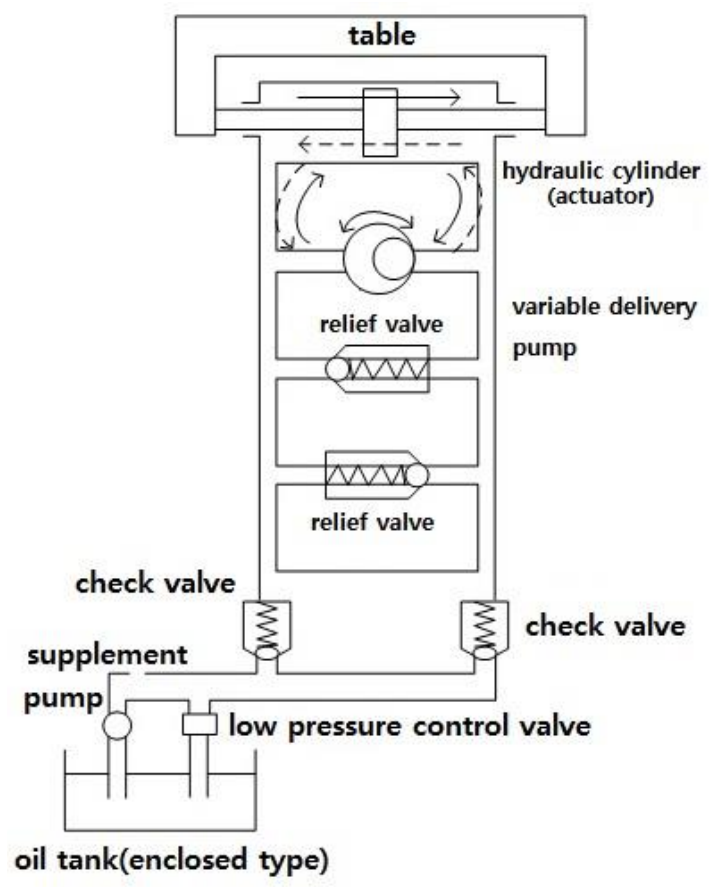

Figure 1. The structure of Hydraulic mechanism

Figure 1 shows the basic movements of hydraulic mechanism. According to the rotation direction of the pump pressure is applied to the oil, and the horizontal movements of the table change. Utilizing this phenomenon many applications are possible. This study tries to operate the generator by applying pressure to the actuator and controlling the interior oil and fluid.

\section{Development of Small Generator Using Hydraulic Mechanism}

This study is to supply necessary electricity through the operation of the LED illumination and the sensor node in the inshore cultivation and open sea fishery regions where the electrical supply from the land can be troublesome. And this is a study of wave force which has a diverse application potential among the marine New Renewable Energy and relevant domestic researches.

\subsection{Small generator structures using a hydraulic mechanism}

There are three major particulars in the construction. First, it is self-electric power generation. This is to supply electricity for the sensor node and LED illumination in the 
marine environment where there is no provision of electricity from the land. Second, it is miniaturization and lightweight orientation. Since it is to be installed in the cultivating location or on a floating object like a buoy. So the minimization of the impact on the structure itself through the lightweights and miniaturization is crucial. Third, it is ample generation capacity. The more an apparatus gets miniaturized, the less the wave force it takes. Thus various structures or additional devices to utilize wave force to the maximum for enough generation capacity should be developed.

Among the oil pressure instruments check valve enabled the existing structure that induces the interior fluid to flow in one direction.
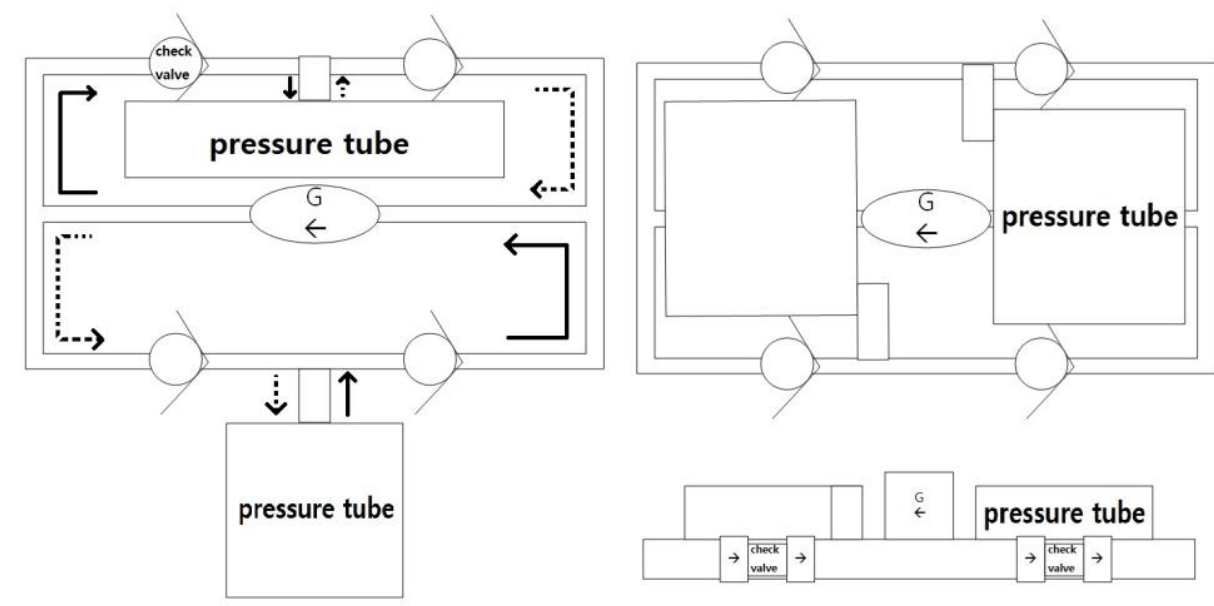

Figure 2. Small generating set structures using hydraulic mechanism

As seen in Figure 2 small generating structures with hydraulic mechanism are composed with oil pressure tube that takes the pressure of ocean wave, check valve which makes the interior fluid flow in a certain direction, and the generator that produces electricity. The generating principle of this apparatus using hydraulic mechanism is to produce electricity when the oil pressure tube gets pressure, the fluid in the oil tube moves in a direction through the check valve and passes through the generator to produce power [6].

Shen Zhen $2 \mathrm{U}$ of China produces the hydroelectric power generator adapted to a small generating device using hydraulic mechanism, and the $3.6 \mathrm{~V}$ micro hydroelectric power generator sold in http://www.seeedstudio.com/ was selected [7]. The operating pressure is $0 \sim 2 \mathrm{Kgf}$ and the voltage and the magnitude of electric current are $3.6 \mathrm{~V}$ and $300 \mathrm{~mA}$ for enough electric supply.

\subsection{Prototype analysis}

The structure seen in Figure 3 was finally constructed through the prototype manufactures. In the above Figure 3 the structure of a small generator using hydraulic mechanism adopted the standard diameter of 3/8inc for all the parts except the generator that has a diameter of $1 / 2$ inc. This is because the diameter of the tube should be $3 / 8 \mathrm{inc}$ at least to allow the minimum amount of fluid for a smooth movement inside the structure in order to generate power. Check valve was made of plastic and the tube of P.B material in $\mathrm{L}$ and $\mathrm{T}$ beams, so the lightweight orientation was fulfilled in an awesome way. The oil pressure tube was made of supple plastic lest it should convey pressure even with little energy. However there arose a 
question for the actual application possibility because the diameter of the tube was not wide enough even with the operation using LED.

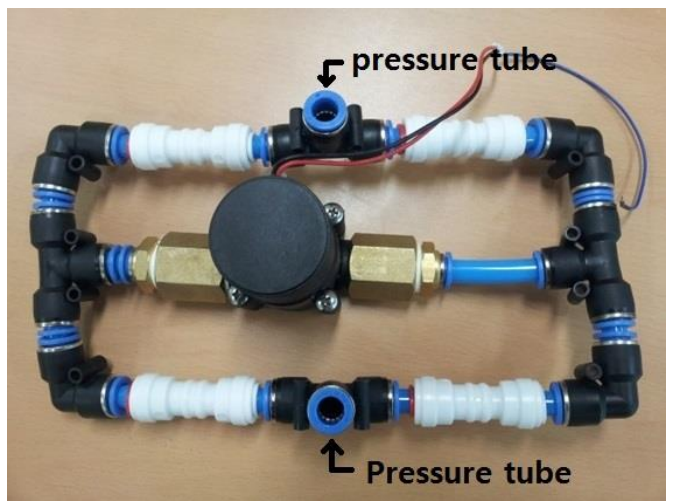

Figure 3. The final prototype

\section{Experimental Procedures and Results}

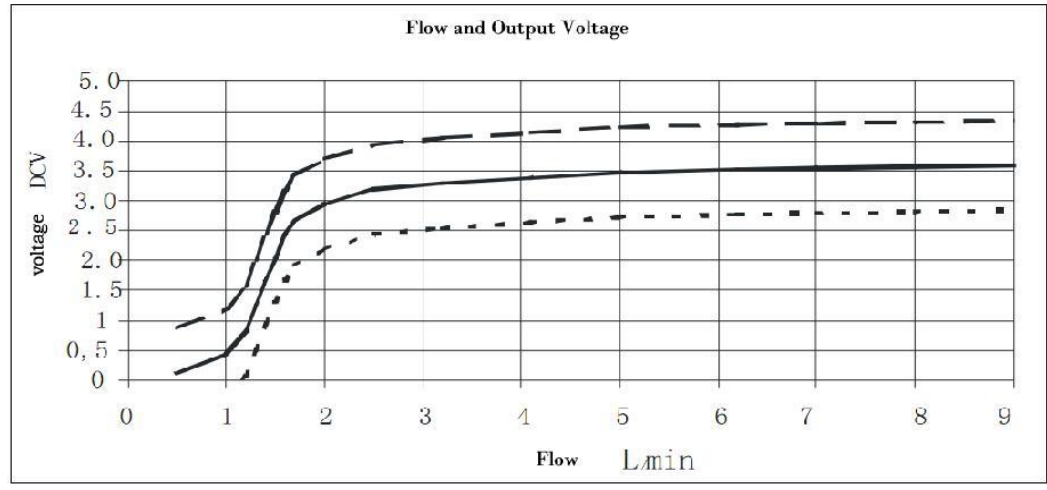

Figure 4. Flow and Output voltage Diagram

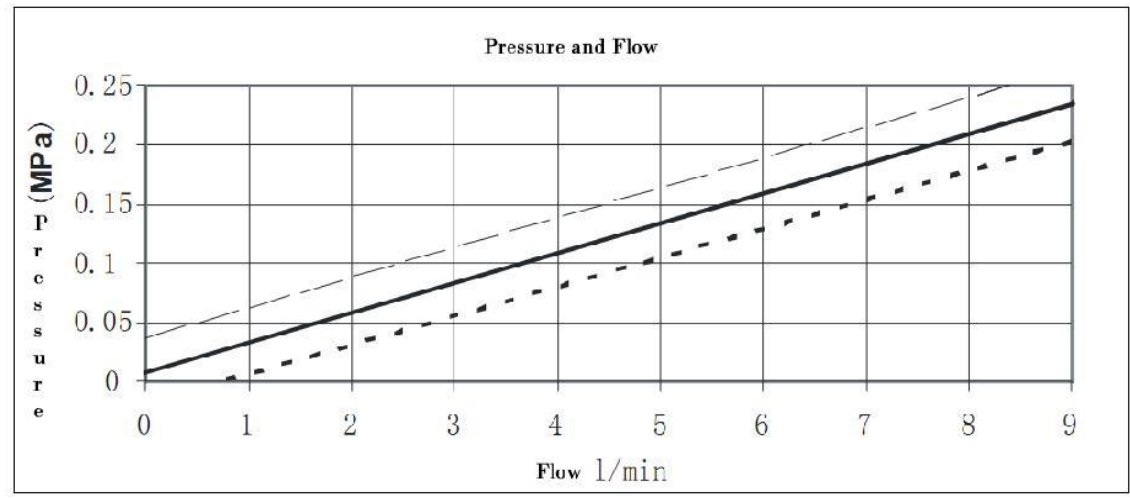

Figure 5. Flow and Pressure diagram

Since before the derivation of the experimental results there was no device to measure the interior pressure and speed of the fluid, Flow and Output Voltage Diagram from 
http://www.seeedstudio.com/[7] was adopted to analogize the minimum pressure and velocity of the fluid. As seen in Figure 4 if there flows $2 \mathrm{~L}$ of water per minute, there comes out $3.0 \mathrm{~V}$ of enough generating power. Figure 5 shows that $2 \mathrm{~L} / \mathrm{min}$. produce $0.07 \mathrm{MPa}$. Also through the test the minimum force to act on the oil pressure tube is $0.07 \mathrm{MPa}$.

In order to investigate the possibility of actual application of the final prototype the voltage at each resistance was measured. Figure 6 shows the change of voltage and electric power according to each resistance together with the supply capacity. When the loaded resistance was $200 \mathrm{ohm}$, the uniform $3.6 \mathrm{~V}$ of voltage was confirmed. And when the loaded resistance was $4 \mathrm{ohm}$, the electric power of $1.21 \mathrm{~W}$ hit the maximum peak.

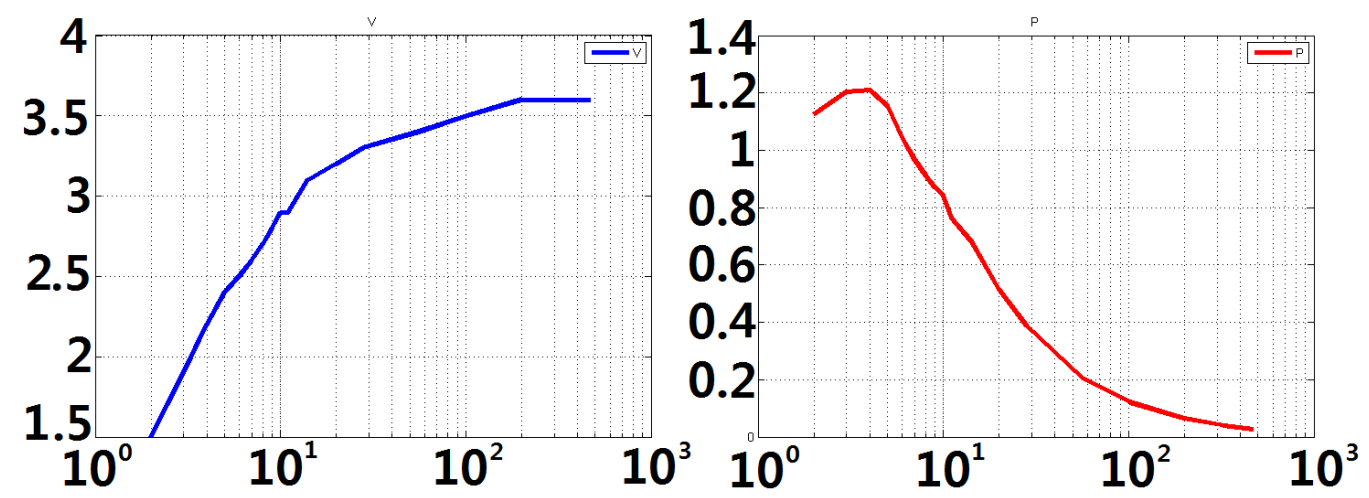

Figure 6. Generated voltage and generated Power by the load resistance

The sensor node operation test confirmed that the necessary voltage is $3.3 \sim 3.8 \mathrm{~V}$, and the electric current is $300 \sim 500 \mathrm{~mA}$ with the sensor node [8] in Figure 7 at a normal operation.

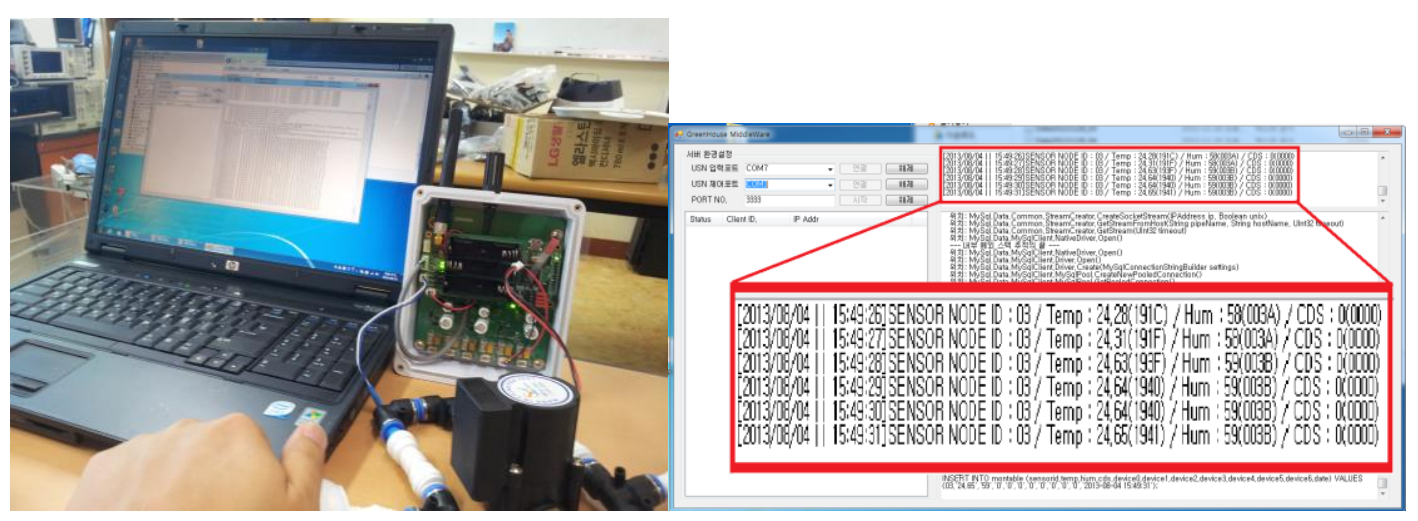

Figure 7. Sensor nodes operating tests

\section{Application plan}

Figure 8 shows that small generator using a hydraulic mounted on outer wall of fish farm. Buoy moves up and down with the motion of the waves. Buoy pushes the pressure tube generating continuous power. 


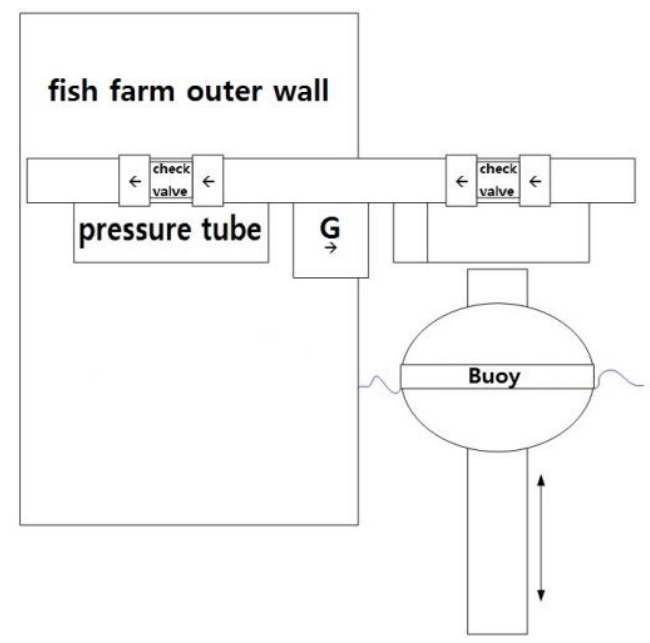

Figure 8. Application structure

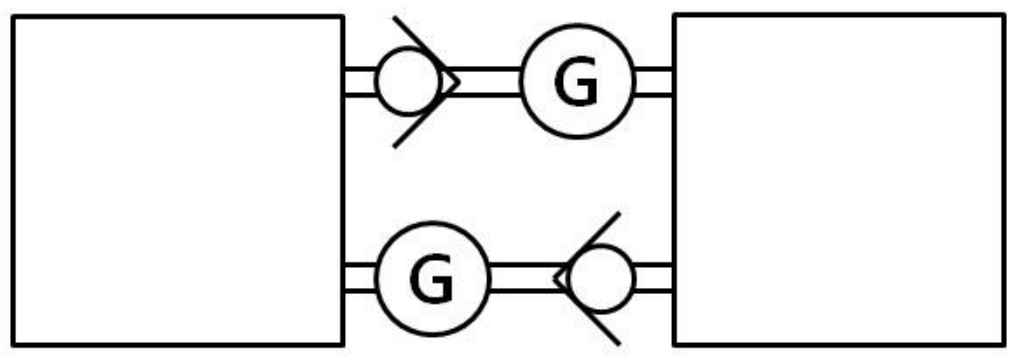

Figure 9. Structure of the two generators, two check valves

Figure 9 shows that using two generators, check valves, the length of the tube can be reduced which results a smaller size as well as a simpler structure.

\section{Conclusion}

The completed small generating apparatus using hydraulic mechanism can be used directly at a marine cultivating location. The improvement in performance was possible in that the pressure and velocity of the fluid were increased by the exposure at a much more wave force to supply much more electricity. This study found out that the thickness of the tube > oil pressure tube > the length of the tube in turn affect the pressure and velocity of the fluid. Also it confirmed that the velocity much more than the pressure of the fluid impacts the power generation. To raise the velocity of the fluid the thickness of the plumbing should be large. And the supple material in the pressure tube is essential.

It is planned that hereafter this structure should be adapted to a real cultivating location for a test and that various applied structures should be developed for further improvements. 


\section{Acknowledgements}

This work was supported by the Industrial Strategic technology development program, 10041766, Development of energy management technologies with small capacity based on marine resources funded by the Ministry of Knowledge Economy (MKE, Korea).

\section{References}

[1] H. J. Cheon, J. M. Sohn, B. W. Nam, S. H. Shin and K. Y. Hong, "A Structural Responses of Floating Pendulum Wave Energy Converter under Wave", The Korean Society for Marine Enviornment and Energy, (2012), pp. 55-63.

[2] Korea Energy Management Corporation Renewable Energy Center, https://www.renewableenergy.or.kr/trd/policy/policytrend/selectPolicyTrend.do?nttId=14374\&bbsId=BBSM STR_000000000161\&pageIndex=1\&searchCnd=\&searchWrd=\&searchNation=\&searchEnrg=\&nttSeCode=.

[3] Wikipedia. http://en.wikipedia.org/wiki/Wave_power.

[4] D. H. Jeong, "Wave Energy generation Market Trends and Strategies", KISTI MARKET REPORT, vol. 2, Issue 8, (2012), pp. 20-23.

[5] Naver Knowledge Encyclopedia, http://terms.naver.com/entry.nhn?cid=368\&docId=412790\&mobile \&categoryId $=368$.

[6] Wikipedia, http://en.wikipedia.org/wiki/Hydraulic_drive_system.

[7] B. Drew, A. R. Plummer and M. N. Sahinkaya, "A review of wave energy converter technology", Proceedings of the Institution of Mechanical Engineers, Part A: Journal of Power and Energy, vol. 223 no. 8, (2009) December 1, pp. 887-902.

[8] Seeed WIKI, http://www.seeedstudio.com/wiki/index.php?title=3.6V_Micro_hydro_generator.

[9] H. S. Cho, Y. Y. Cho, C. S. Shin and J. W. Park, "A Study on Renewable Energy Harvesting and Circuit Design Based on a Maximum Power Point", International Journal of Multimedia and Ubiquitous Engineering vol. 8, no. 2, (2013), pp. 111-122.

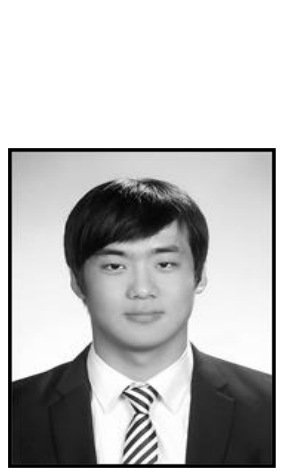

\section{Authors}

\section{Yeongseok Lee}

Yeongseok Lee received the Bachelor's degree in Information \& Communication engineering from Sunchon National University in 2013. $\mathrm{He}$ is a Master's course student of Sunchon University. He is also a researcher of Go-Lab at Sunchon National University too. His research focuses on Localization and renewable energy harvesting and Embedded System and RFID/USN technologies.

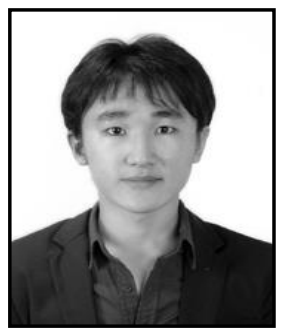

\section{Hong-geun Kim}

He received the BS and MS degrees in Information \& Communication engineering from Sunchon National University in 2011 and 2013, respectively. Currently, he is a $\mathrm{PhD}$ student in Sunchon National University. His research focuses on Localization and renewable energy harvesting and Embedded System and RFID/USN technologies. 


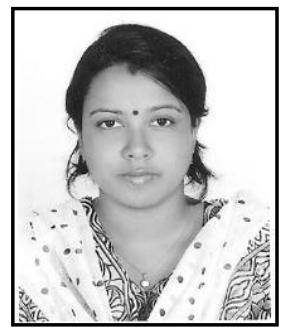

\section{Olly Roy Chowdhury}

She received the BS and MS degrees in Applied Physics Electronics and Communication Engineering, University of Dhaka, Bangladesh in 2006 and 2007, respectively. She is a lecturer of the Department of Physics and Mechanical Engineering, in Patuakhali Science and Technology University, Bangladesh. Currently, she is a PhD student in Sunchon National University. Her research focuses on renewable energy harvesting and communication engineering.

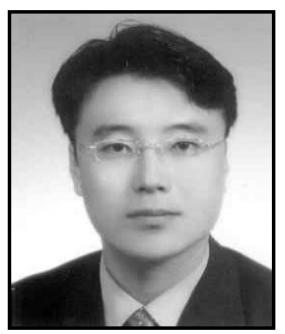

\section{Changsun Shin}

Changsun Shin received the $\mathrm{PhD}$ degree in computer engineering at Wonkwang University. Currently, he is an associate professor of the Department of information \& communication engineering in Sunchon National University. His main research interests include Distributed Real-Time Computing, Distributed Object Modeling, Ubiquitous Agriculture and Ubiquitous Sensor Network (USN).

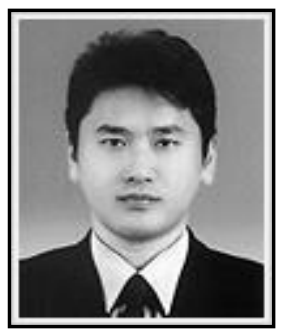

\section{Yongyun Cho}

Yongyun Cho received the $\mathrm{PhD}$ degree in computer engineering at Soongsil University. Currently, he is an assistant professor of the Department of information \& communication engineering in Sunchon National University. His main research interests include System Software, Embedded Software and Ubiquitous Computing.

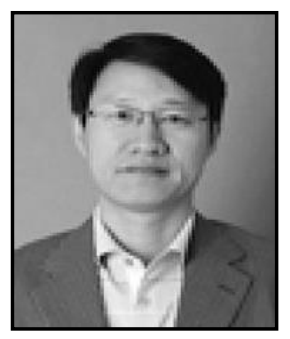

\section{Jangwoo Park}

He received the $\mathrm{BS}, \mathrm{MS}$ and $\mathrm{PhD}$ degrees in Electronic engineering from Hanyang University, Seoul, Korea in 1987, 1989 and 1993, respectively. In 1995, he joined the faculty member of the Sunchon National University, where he is currently a professor in the Department of Information \& Communication engineering. His research focuses on Localization and SoC and system designs and RFID/USN technologies. 